\title{
Thoughts on The Marketing Mode of Le TV \& Super TV
}

\author{
Aimin $\mathrm{Li}^{1}$ and Jiajia $\mathrm{Han}^{1}$ \\ ${ }^{1}$ Management Engineering Department, Zhengzhou University, Henan province, China
}

\begin{abstract}
Motivated by the nation's policy of Tri-networks integration, the maturity of technology platform, and the user's demand, more and more enterprises start to launch the research of smart TV. In order to offer the reference to other smart TV enterprisers, the status of the smart TV industry is presented in this thesis. The mode of operation and profitable of Le $\mathrm{TV} \cdot$ super TV, is also discussed, as well as the underlying problems during its development.
\end{abstract}

Keywords. Smart TV, LeTV, CP2C.

\section{Introduction}

20 years ago, the combination of computers and the Internet, so that only the original calculation, office tools, computers have become almost omnipotent, Google, Tencent and other strong rise; 5 years ago, mobile phone and Internet combination, so that the original communication tools are mobile phones have colorful, from Apple to dominate the world. Past experience tells us that once the combination of traditional products and the Internet, it is possible to change the fate of this product, at the same time will spawn a number of great enterprises. Today, crossborder convergence of television and the Internet should be a major trend in the future.

Market research firm NPD Display Search research data show that in 2011 China's smart TV market total of 400 million units in 201216.75 million units in 2013 reached 26 million units, all the way up. At the same time, Orville Consulting released the first quarter of 2013 TV brand sales data show that the smart TV market penetration has reached $37.2 \%$, compared with $19 \%$ in 2012 increased nearly doubled, 2015 smart TV market penetration will rise To $90 \%$. CCID Consulting also predicted that the next three years, China's smart TV production scale annual compound growth rate is expected to reach $65.1 \%$, which means that smart TV will soon become the protagonist of the TV market. Can be expected, the blowout of the industry will bring to home entertainment a huge change. In view of this, the music TV • super TV turned out worth pondering.

\section{Le, Le TV • super TV}

The so-called smart TV, is the same as smart phones, with a full open platform, equipped with the operating system, you can install and uninstall the software, games and third-party service providers to provide programs, through such programs on the color TV function To expand, and can be wired, wireless network to achieve the Internet surfing such a general term for color TV [1]. Simple point of view, the arrival of smart TV, conform to the TV network, highdefinition, intelligent trend, but also is expected to break the traditional TV getting lower and lower the situation.

November 2004, Le established, announced in 2007 earnings, August 12, 2010 listed on the GEM in China, the video industry is the world's first IPO company, is currently the only Chinese A-share listed video company. When other video sites are still a substantial loss of time, it has continued to profit; when other video sites for copyright hit, it took the film and television distribution rights to sit to bid; when other video sites still standing in the radio and television door Outside the wandering, it has become a television manufacturer [2]. Le, Le TV, music video industry as the three major business lines is the main business as music, the introduction of Le TV • super TV is completed the whole industry chain layout.

Le relies on its own "content + platform + terminal + application" video marketing ecological chain to redefine the traditional TV, 416 engineering staff, after 1253 days to build Le TV • Super TV has 107 patents, 54 copyright, R \& D personnel are no longer limited to the TV itself, but focus on creating a complete eco-system based on the big screen the super configuration + experience LeTV UI system + for large screen Letv Store + China's largest film library + super Cloud Video Platform $+\ldots$

\section{Smart TV market trends}




\subsection{Smart TV industry policy}

In February 2011, the Ministry of Industry issued a "digital television and digital home industry," second Five-Year "plan", the Ministry of Industry and Information Technology, the Ministry of Industry and Information Technology, , That will be in the "second Five-Year" period to vigorously promote the digital TV industry sales growth, and is expected to 2015, digital television and digital home-based audio-visual industry sales output to achieve "double than 2010" On October 28, the State Administration of Radio Film and Television General Office issued a notice issued by the Office of the "Internet TV license plate operation and management requirements," the notice to allow video content directly or through the set-top box into the TV set Screen, but only if the license must cooperate with, and the content must accept control [3]. So far this smart TV legalization, but the right to operate only 7: CNTV (China Network Television), China, BesTV, South Media, Hunan TV, CRI (China Radio International) and CNR (Central People's Broadcasting Station). January 12, 2012, Le and one of the seven license side of the CNTV reached a strategic cooperation agreement, which for music TV as a platform strategy to open a cut.

From this we can see, the State Administration of Radio on the attitude of smart TV has evolved from a simple regulatory development to encourage the operation, which is the smart TV industry for the first time in years of development. In the triple play environment, based on an open software platform for smart TV will become an important carrier of triple play, play the important task of home multimedia information platform.

\subsection{Smart TV will become the next hot market}

What's the hottest keywords on the Internet in 2013? Not "mergers and acquisitions", not "market", but "cross-border." "Cross-border" in the traditional hardware industry is no stranger to the industry's frequent integration, so that hardware vendors have horizontal cross-border. If the horizontal cross-border hardware is the industry's normal, then the Internet cross-border hardware, in addition to Google outside the world before this is also no two [4]. The Internet industry have to enter the smart TV, for Internet companies is undoubtedly the second collective "collision" (the first time is a smart phone), which is sufficient to prove that the smart TV is a trend in the future. In the real advance of triple play, the implementation of broadband strategy in China and the SARFT issued under the premise of Internet TV license, smart TV is expected to get rapid development.

At present people's viewing habits are moving from the PC to the TV-screen transfer, the traditional TV industry is also facing an important stage of transformation to the living room entertainment, smart TV will gradually become a family entertainment center. The first listed TV business revenue of more than 10 billion US dollars in a research report that Samsung, the modern family to the TV as the living room core, which companies can get control of television business status, to get into the network family business pass, And the gold content of this pass is no less than the PC Internet and mobile Internet.

Data show that in 2012 the average smart TV activation rate of $27.5 \%$, smart TV active users is about $10 \%$, although this figure is slightly lower, but the overall application environment has been formed. August 17, 2013, the State Council issued a "broadband China" strategy, called for the end of 2015, the basic realization of urban fiber to the home floor, rural broadband into the rural villages, urban families up to 20Mbps. Looking to the future, smart TV is expected to become the smart phone after another hot application.

Figures and tables, as originals of good quality and well contrasted, are to be in their final form, ready for reproduction, pasted in the appropriate place in the text. Try to ensure that the size of the text in your figures is approximately the same size as the main text (10 point). Try to ensure that lines are no thinner than 0.25 point.

\section{Mode of Le TV operation}

\section{1 based on Le unparalleled resources}

Le adhere to the "genuine + paid" profit model, and achieved good results. Internet content playback, the Le TV • Super TV will rely on music sources rich source of film, Le now has more than 90,000 sets of TV series, more than 50,000 film network copyright, monopoly over the past three years, $60 \%$ To achieve more than $95 \%$ of film and television coverage. The number of video sites than the other more than 10 exclusive two times the sum of more than the sum of film and television copyright. In addition there are a wealth of homemade, animation, fashion, documentary and other content, and the industry's most comprehensive sports events, covering La Liga, Serie A, Ligue 1, Super League, AFC Champions League, CBA and other top events. According to Le Watch their own description, they hold the copyright of the film and television assets in 2007 is about 1.87 million yuan, but by 2011 has been as high as 855 million yuan, an increase of 450 times in 4 years, which undoubtedly provides Le TV Strong competition.

\subsection{Le TV to create the public marketing model}

Le TV as the pioneering use of "CP2C" mode (public marketing), so that as the TV TV • TV direct access to the whole process. The so-called "CP2C" (customer planning to customer), is initiated by the consumer products, as well as some of the flexible requirements of the DIY to the manufacturers, and manufacturers in the next single from the time, you 
can give the whole production schedule and Product tracking. It has two meanings: one is to allow consumers to put forward their own needs, to achieve targeted production; the second is to change the past in accordance with the batch production, and by the order to drive production [5]. Obviously, "CP2C" model can not only achieve the product's individuality, but also greatly shorten the product update cycle.

Le CEO Jia Yue Ting said that with the social media and online video era, the existing marketing model is out of date. R \& D, dissemination, sales, after-sale and operation, recycling to product design closed-loop every link can be the whole process of direct access to the user, and the user can be deeply involved in the whole process of each of the "CP2C" mode, the realization of product design. A link, truly "tens of millions of people discontent, millions of people involved, tens of millions of $\mathrm{R} \& \mathrm{D}$, tens of millions of people to use, millions of people spread." In the design and research and development, "CP2C" allows users to "custom DIY", and truly create a suitable interest and demand for products; sales, Le TV with "custom DIY + continuous sales" instead of "hungry marketing", That is, start the open pre-sale mode, the purchase and payment channels will be long-term open, consumers do not need to make an appointment and buy; while "CP2C" mode in the dissemination of more efficient, music TV will give full play to the value of social communication, in addition to micro- And other widely used means of social communication, will also play Le the first professional long video site advantage, play the Le the ecological fusion effect.

\subsection{The profit model of Le TV}

With the traditional home appliance manufacturers to do the largest scale to maximize the cost-sharing, that is, with the scale for low-cost completely different, Le the road is to use low-cost in exchange for the scale. Le the purpose is to first take a low-cost hardware circle massive users, and then by charging content service fees to earn real money, and ultimately create a traditional TV manufacturers do not have the "content + platform + terminal + application" of the ecosystem. Its core profit model is to use music TV $\bullet$ super TV to open up its integration with the network port, smart TV APP application development, while expanding the audience, then through its additional services and advertising revenue.

"Technology + copyright" two-wheel drive, "science and technology + entertainment" dual gene, Le the "content + platform + terminal + application" vertical industry chain integration equivalent to multiplication effect, leading the upstream and downstream industry chain performance doubled release. Content is the basis for the application of valueadded services, intelligent TV terminal is to provide users with a good experience, and ultimately build cloud video open platform. Traditional TV manufacturers can only rely on hardware sales of this single business model, because they have no real control of content and platform operations, can only be a device manufacturer. The music can open up with its cloud video platform and massive copyright content, providing rich content and applications to change the profitability of traditional television models and the establishment of new business model, a single hardware sales profit upgrade to "content revenue + hardware Income + terminal advertising + application into "the four sources of income. Super TV's four-fold profit model, making music TV • Super TV no longer rely on hardware profits, so super TV pricing more flexible.

As of September 2013, the average daily average UV (Unique Visitor) 23 million, peak 32 million, average daily PV (Page View) 110 million, average daily VV1.2 (Video View) billion peak 160 million. If you can convert this level of video users into super TV users, to pay 490 yuan per household annual fee calculation, music will be earned as a bowl full of surplus. Not only that, China has 230 million TV users, if you can win 500 million end-users, according to the annual fee of 490 yuan revenue, Le an annual increase of 2.5 billion. If coupled with advertising revenue, music, when the credit is even more expensive.

\section{Thinking on the Le TV • super TV}

\subsection{Industry competition}

Music TV as the first day of opening an appointment on the approximation of 20,000 people, higher than the number of works machines sold nearly 100 times; almost the same time, including Changhong, a number of traditional household electrical appliance enterprises have also introduced 60 -inch new products, the price of Of the low-music TV. However, Haier, Changhong, Samsung and other companies to introduce low-cost products is actually a competitive strategy, hoping to suppress a single product to suppress super TV, because Le, the traditional TV companies have a full range of products, through other models Complementary form to maintain the super TV siege. On the other hand, with the Le TV - super TV frontal confrontation, not only the traditional TV manufacturers. September 3, 2013, the video site leader Fantasy together with the TV giant TCL jointly launched the smart TV "TV +", massive video content, announced the "free life", which is equal to completely cut off the music charges, September 5 millet In Beijing National Convention Center held a new conference, introduced millet TV ......

\subsection{Profit model to be market test}

Le the 2012 earnings report, the annual operating income of 1.167 billion yuan, while Le only 75 million paid subscribers, high-definition video services revenue of only 1.5 billion. Obviously, Le the pay conversion rate on the 
Internet is still very low, therefore, Le TV UI smart TV platform, how much money from the user that circle, it is necessary to put a big question mark. Apple's revenue for the second quarter of 2013, for example, from the Mac revenue of $\$ 5.447$ billion; from iPone's revenue of 22.95 billion US dollars; from the iPad's revenue of 8.476 billion US dollars; and from iTunes / software / services Revenue was only 4.114 billion US dollars. Even if it is to open up the whole industry chain of Apple, its main revenue is still from the hardware products, rather than content services [6].

On the other hand, the charging model does not seem to be "national conditions", at least the current level of acceptance is not very high - too many free online resources, not all movies and television programs have to see highdefinition. For the future of TV renewals (Le TV • super TV service fee of 490 yuan / year), can achieve the "must" point is still unknown.

\subsection{Logistics short board}

As a result of its self-built platform for the sale of music video TV • super TV, the implementation of the channel to the strategy, not with third-party electronic business and channels to cooperate, which means Le the need for a strong logistics system backing. July 3, 2013, as the TV TV • super TV officially on sale, ten thousand TV sold out in 49 minutes, but the problem ensues, in the sale of two weeks, still ordered the first batch of super TV consumption The customer service phone is always busy, even if fortunate enough to get through the customer service phone, they can not be promised in the customer service within the time to get back ...... music promise to order the user's spot "Arrived at the regional transit center, the core city (North Canton wide) orders the next day, two cities (regional transit centers covered by the city) orders every other day," but the reality and commitment vary widely.

\section{References}

1. Xu Jian. Smart TV technology and industry development status and trends. Cable TV technology, 2012, 3: 93-96.

2. Chen Xinyan. Super music super TV. China Small and Medium Enterprises, 2013,7: 26-29.

3. Wang Chuanzhen. Triple play under the background of the Internet TV business development. Radio and Television Information, 2012,10: 47-49

4. Ma Zhenmin, Li Xin, Wang Ziju. Cross-border new "as" wild. Successful marketing, 2013,9: 37-38.

5. Zhang Nan. Comments: Le "public marketing" really can subvert it? .http://tech.163.com/13/0508/00/8UAIBTB9000915BD.html, 2013-05-08.

6. Zheng Yuanchun, Cui Jing. Lonely Le. Chinese Economy and Informationization, 2013,20: 73-75. 